\title{
The Difference in Visual Skills Between Expert Versus Novice Soccer Referees
}

\author{
by \\ Abdullah Ghasemi ${ }^{1}$, Maryam Momeni ${ }^{2}$ Meysam Rezaee ${ }^{3}$, Amin Gholami ${ }^{4}$
}

The aim of this study was to compare the visual skills of expert and novice soccer referees. Twenty expert soccer referees, twenty two novice soccer referees and twenty non-athletes male students were investigated for facility of accommodation, peripheral vision, eye saccadic movements and speed of recognition. The results showed that the expert soccer referees were superior in all of the visual skills, but there was no significant difference between novice referees and non-athletes. This substantial difference between expert and novice soccer referees implies that these visual skills are important for refereeing soccer. For detecting other visual skills in soccer, referees must use visual skills from other programs. This study suggested that talent identification and development of visual abilities among soccer referees is of fundamental importance to success.

Key words: visual skills, soccer referees, expert, novice

\section{Introduction}

In the second century, Galen (131-201 A.D.) believed that there was a relation between ball sports and body and visual status (Hitzeman \& Beckerman, 1993). Despite this primary point of view about the visual importance in sports, it has been forgotten for many years. In the middle of the $20^{\text {th }}$ century, new scientific opinions for sports were developed. It is commonly believed that sports involve a multi-disciplinary approach. All sports games develop human sensory and motor systems. However, every sport may influence a specific body system, selectively (Jafarzadehpur \& Yarigholi, 2004).
The awareness that skilled perception precedes appropriate action, has led researchers to examine its role in sport performance. For example, it has been demonstrated that experts are better than novice in visual skills requiring sports vision. The difference in visual skills between expert and novice athletes was initially examined in university athletes (Vaeyens et al, 2007). Montes-mico et al. (2000) used this approach in soccer players. In this study, expert soccer players were better than non-athletes in eye-hand and eye-foot visual reaction times. Also, Jafarzadehpur and Yarigholi (2004) have shown that elite table tennis players have high abilities in facility of accommodation and visual acuity, in comparison to non-players.

\footnotetext{
1 - Research and Science Branch of Islamic Azad University.

2 - University of Rehabilitation and Welfare / Tehran/Iran

3 - Mashhad Branch/Islamic Azad University/Tehran/Iran

4 - Sport Science Center/ Tehran/Iran
} 
One of the important elements in decision making relies upon the athlete's visual skills (Savelsbergh et al., 2005; Panchuk \& Viskers, 2006; Vaeyens et al., 2007). Although the task of selecting the next best move has been suggested to be the most successful method of evaluating expert performance (see Helsen and Pauwels, 1993; Ward and Williams, 2003), there has been relatively limited research on the strategies employed by athletes when making such decisions, especially in soccer.

Although researchers have made significant progress in outlining some of the factors that contribute to successful decision making (i.e., the task of selecting the next best move in an offensive situation (Jafarzadehpur \& Yarigholi, 2004), knowledge of the mechanisms underlying performance remains somewhat limited (Williams and Ericsson, 2005). For example, a few researchers have examined the role of visual skills in athletes when making such decisions (Savelsbergh et al., 2005). Zhang \& Watanabe (2005) examined the difference in saccadic latency and express saccades between skilled and novice ball players. They required participants to make a decision quickly and accurately when a stimulus was presented. Skilled ball players had shorter mean saccadic latency than novice players.

Ludeke and Ferreira (2003) evaluated the difference in visual skill level of professional versus nonprofessional rugby players. The results indicated that the professional players outperformed the nonprofessional players in all visual skills: eye-hand coordination, eye-body coordination, central-peripheral awareness and visual reaction time.

Expert soccer referees must have good visual skills to make good decisions quickly and accurately in different situations. Such skilled behaviors require many years of practice, together with a considerable amount of ability (Williams and Ericsson, 2005). It is now accepted that successful performances in such a sport, requires skill in perception, as well as efficient and accurate execution of movement patterns (Williams \& Hodges, 2005).

As cited in a wealth of literature reviews, the majority of researchers have focused on the differences between visual skills among expert and novice athletes, and have investigated the correlation of these skills with accuracies in decision making (Williams et al., 2002). Very little has been written about visual skills in referees. An important question is whether soccer referees need superior visual skills in comparison to non-athletes? In the current study, we examined the difference in visual skills between expert and novice soccer referees.

\section{Methods}

Forty two referees and twenty students participated in this study. The participants were classified in three groups according to their experience and refereeing level. The expert group consisted of 20 experienced referees (Age $=36 \pm 1.2$ years) who had been refereeing soccer for an average of $12 \pm 1.8$ years, holding elite referee ranking in Asian Football Confederation (AFC). The majority of expert participants had actively participated in the Iranian premier soccer league. The novice group included 22 (Age $=22.6 \pm 0.4$ years) soccer referees form the Tehran adolescence soccer league. They all held the third referee degree license. This group had been refereeing soccer for $2.3 \pm 0.3$ years. The control group included 20 university students (Age $=22.1 \pm$ 0.3 years) who had no experience in refereeing. The latter participants had limited or no soccer experience. Informed consent was obtained prior to participation. Ethical approval was provided through the Iran medical university hospital.

\section{Measures}

The following visual skills were assessed:

1. Facility of accommodation measured by Rock lenses.

2. Peripheral vision evaluated by tangent screen

3. Speed of recognition measured by Optosys software

4. Eye saccadic movement at $40 \mathrm{~cm}$ distances measured by Merely Sequential Fixation (MSF; Griffin, 1988).

The entire tests for three groups were done in the optometry clinic of Iran University of Medical Science (IUMS).

\section{Design and data analysis}

After preliminary exams (i.e., visual acuity, objective refraction, ocular motility and ophthalmoscopy), a code was assigned to every person and divided into two groups. An optometrist, whom did not know about subject's group, measured these 4 skills. He used +/- 2.00 sphere lenses for accommodation facility. A near chart was positioned at $40 \mathrm{~cm}$ in front of the participants. They were instructed to fixate at the 20/25 row in a well-illuminated examine 
room (Griffin, 1988). The participants were requested to read aloud every optotype that the optometrist requested. At the same time the flipper was changed. Participants were asked about clearance of optotypes. The optometrist waited for clear vision in every change of the flipper. He counted the cycles of flipper changes per minute as a criterion for accommodation facility.

For measuring gross saccadic eye movement (SEM), the optometrist held the saccadic board in front of participants eye (40 cm distance) and asked the participants to change their fixation point (with optotypes on the board) as fast as possible in $1 \mathrm{~min}$ ute. Then he counted the cycles of correct fixation.

Speed of recognition was assessed by Optosys software. The participant sat in front of monitor of a computer on a comfortable chair. Different geometric shapes (star, square and triangle) were shown randomly on the monitor. The participants were requested to redraw the presented shape in 5 seconds. The shapes and its position were changed randomly in one minute. The examiner counted the number of correctly drawn shapes in that time.

Fine and gross saccadic eye movement was evaluated by the Optosys system. Random dots in one millimeter diameter were presented on the monitor. Every point lasted on the monitor about one second. The participants were required to mark the point as fast as possible. Then optometrist counted the number of correctly marked points on the display in one minute.

The last item evaluated was peripheral vision. This test evaluates visual motor response to peripheral stimuli in eight visual field locations. The subject sat in front of a tangent screen and maintained his fixation on the center of screen. The optometrist brought the different colored circles gradually from peripheral field to the center of screen. Whenever subject recognized the color and position of circle, the test was stopped and the distance of the test object was measured from the center. This action was repeated in eight different meridians.

All data was recorded on a specific card which was uniquely coded for every person. To measure the significance of differences between the groups, we used a one way analysis of variance (ANOVA). Sheffe post hoc tests were then used to establish significant effects. The data was statistically analyzed by the statistical package for social science (SPSS) version 15.

\section{Results}

To determine the difference between visual skills in expert and novice soccer referees, we compared the facility of accommodation, peripheral vision, speed of recognition and fine and gross saccadic movements among these two groups and control group.

The data analyses with ANOVA and Sheffe tests revealed significant $(p<0.01)$ differences between expert soccer referees and the other two groups in all visual skills, but there was no difference between novice and control group.

As shown in Table 1, facility of accommodation of expert soccer referees is significantly $(\mathrm{P}<0.01)$ better than the other groups. In the facility test, the frequency of clearance in expert referees was $12 \mathrm{cpm}$, but in novice referees and control group, it was 7 cpm. Saccadic eye movement is also significantly $(\mathrm{P}<0.01)$ better in expert referees. In this skill, the number of eye movements of expert referees was 86 , while in novice referees it was 68 and in the control group it was 63 (Table 1).

Peripheral vision in expert referees is higher than other groups. The average distance from center of the board was $78.26 \mathrm{~cm}$, but in novice referees and control group, $51.47 \mathrm{~cm}$ and $50.48 \mathrm{~cm}$, respectively, were recorded. The expert referees outperformed the novice referees and control group in speed of recognition. The number of points in one second was 58.54 in expert referees, whereas in novice referees and control group, 52.18 and 52.00, respectively, were established.

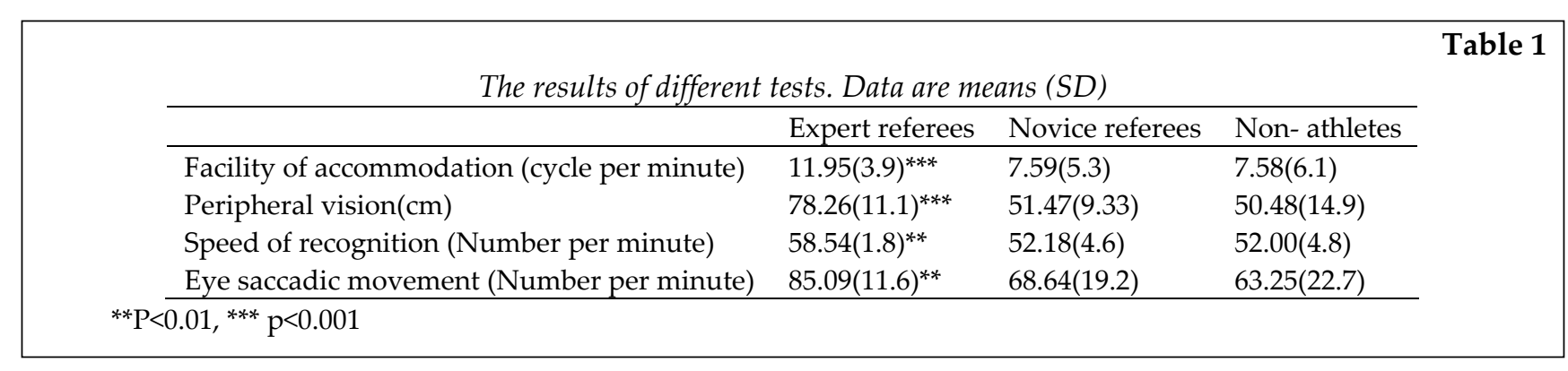




\section{Discussion}

The purpose of the study was to compare visual skills between expert and novice soccer referees.

According to the results of the study, all of the visual skills were significantly better in expert soccer referees. The results are in agreement with the findings of Jafarzadehpur and Yarigholi (2004) and Montes-Mico et al. (2000).

Facility development may shorten the time that the visual system needs for taking a clear image. In expert referees, fixation point changes as fast as ball and player velocity changes. The velocity of ball and players is very high, and thus the eyes should clearly see them. Therefore, any person that can effectively follow the ball would be more successful as a referee (Jafarzadehpur \& Yarigholi, 2004). Saccadic eye movements are used for fixation on the ball, while suppression takes place in saccadic eye movements without fixation (Rippol \& Latiri, 1997). Only the first and last point of fixation can be seen, and along the saccadic path way these motions are suppressed (Rippol \& Latiri, 1997). Therefore, the first and last point is very important from a visual acuity point of view (Jafarzadehpur \& Yarigholi, 2004). An expert soccer referee should change his accommodation as fast as one's saccadic eye movements for successful achievement and this involves the combination of facility of accommodation and eye saccadic movements.

The results of this study are in agreement with the results of studies about visual search and it relationship with decision making behaviors. Vaeyens et al. (2007) have shown that expert soccer players, in comparison with novice group, used more goal-oriented visual search strategies, such as more number of fixations, less fixation duration and faster interfixation rate. Expert players also fixated for a higher proportion of the time on the player in possession of the ball and used a higher inter-fixation rate than the novice players (Vaeyens et al., 2007).

This finding is possibly due to higher skill in eye saccadic movements and facility of accommodation in expert soccer referees and the amount of their experiences in changing their fixations selectively on the ball and players.

Peripheral vision is another skill that was evaluated in this study. As shown, there was a significant $(\mathrm{P}<0.01)$ difference between expert referees and the other two groups. In stressful conditions in sport, sympathetic nervous system dominates, as would be the case under stressful sporting situation, the per- ceptual system will rely more on peripheral stimuli, and it is for that reason that the pupil dilates and accommodation is relaxed (Ferreira, 2003). This system relies on the peripheral stimuli, rather than central stimuli, which is known as the ambient system (Ferreira, 2003). One of the main functions of the ambient system is detection of movement. Thus, in refereeing, a referee should have a wide peripheral vision to see all of the elements in the field, such as players, ball, assistant, etc. For example, in the scene of a corner kick, the referee should observe all players (for detecting fouls), ball (for tracking it to the goal) and assistant (for detecting off-sides). It seems that a higher level of visual perception in athletes is more related to recognition of speed and responsiveness to stimuli, than functioning of the visual system in the peripheral field. However, some researchers argue that sport disciplines which require multiple stimuli involvement of visual perception improves peripheral vision (Zwierko, 2007). For example, Blundel (1982) investigated peripheral vision in tennis players of different sport levels, from novice to international players. Peripheral sensitivity was determined using different color lights. Results show that these elite athletes had a significantly wider field of vision than novice athletes with regards to white and yellow.

The last skill that was assessed in this study was speed of recognition. According to the results of the study, speed of recognition in the expert referees was significantly better than novice referees $(p<0.01)$ and control group $(\mathrm{p}<0.05)$, which are in agreement with the results of Beckerman and Hitzeman (2003) and Stine et al. (1982). In this case, the results do not support Abernethy and Neal (1999), in that there was no significant difference between expert and novice clay target shooters. Maybe the reason of this discrepancy is that clay target shooting is a static skill and there is no need to move regularly and to continuously observe all activity on the field. For this reason, they have not promoted their peripheral vision. This discrepancy is in accordance with this theory that visual involvement varies according to the environmental demands, and therefore, an athlete's visual characteristics vary according to the sports in which they specialize (Yuan et al., 1995). The most limiting factor in soccer refereeing is time. Time management is critical in all situations, because the referee must make decisions within seconds. In these situations, having a high skill in speed of recognition 
may help them to make good decision in subtle scenes.

The conclusion, thus, is that the professional players performed better in all visual skills. This is in line with previous studies that experts have superior skills in the ability to use visual information, compared to novices (Ferreira, 2002).

Although expert referees performed better than the novices, there is room for improvement in almost all skills, and therefore intervention programs to develop these skills is advisable. It is important to note that no intervention program was completed for the referees in the present study, therefore, no conclusions could be drawn to the assumption that im- provement of visual skills could lead to superior sports performance.

This specific study focused only on the visual skills of the referees. Attention should be given to developing training programs specifically designed to develop these skills. The fact that these results are well below the norms determined by Buys (2002) for elite players, clearly indicates the need for conclusion of specific visual enhancement programs (Buys, 2002). Future studies should also explore the visual skills development between assistant referees. The importance of the relation between visual skills and decision making in soccer referees should also be investigated.

\section{References}

Aberenthy, B. Neal R. J. Visual characteristic of clay target shooters. Journal of Science Medicine Sport, 1999. 2 (1): $1-19$.

Beckerman, S. \& Hitzeman, S. A. Sport's vision testing of selected athletic participants in the 1997 and 1998 AAU. Journal Olympic Games. Journal of Optometry, 2003. 74 (8): 502-16.

Blundell N.L. A multivariate analysis of the visual-perceptual attributes of male and female tennis players of varying ability levels. Psychology of Motor Behavior and Sport: North American Society for the Psychology of Sport and Physical Activity. University of Maryland, 1982. 134-142

Buys, H. The development of Norms and Protocols in Sport Vision evaluation. Dissertation Phil, Department of Optometry, Rand Africans University, Johannesburg, South Africa, 2002. 27-52.

Ferreira, J. T., Sports vision as a hardware and software system. Eyesight July, 2002. 40.

Ferreira, J. T. the application of sport vision in cricket. Eyesight, March 2003. 41-43.

Griffin, J. Binocular anomalies procedures for vision therapy. Professional Press Books, 1988. New York.

Helsen, W. \& Pauwels, J. M. The relationship between expertise and visual information processing in sport. In J. L. Strakes \& F. Allard (Eds.) 1993. Cognitive issues in motor expertise (pp. 109-134). Amsterdam; North-Holland

Hitzeman, S. A. and Beckerman, S A. What the literature says about sports vision. Ed: L. Press. Optometry Clinical 3, 1993. 145-169.

Jafarzadehpur, E. and Yarigholi, M. R. Comparison of visual acuity in reduce lamination and facility of ocular accommodation in table tennis champions and non-players. J sports science and medicine, 2004. 3, 44-48.

Ludeke, A. \& Ferreira, J. T. The difference in visual skills between professional versus non-professional rugby players. Journal of South Africa optometry, 2003. 62 (4): 150-158.

Montes-Mico, R., Bueno I, Candel, J., Pans A. M. Eye-hand and Eye - foot visual reaction time of young soccer players. Optometry, 2000.71 (12): 775-80.

Panchuk, D, Viskers, J. N. Gaze behaviors of goal tenders under spatial-temporal constraints. Human Movement Science, 2006; 25 (6). 733-52.

Ripoll, H. \& Latiri, I. Effect of expertise on coincident - timing accuracy in a fast ball game. Journal of Sports Science, 1997. 15: 573-580.

Savelsbergh, G. J. Van Der Camp, J. Williams A. M, Ward, P. Anticipation and Visual Search behavior in expert soccer goal keepers. Ergonomic, 2005. 15 (11-14): 1686-97. 
Stine CD, Arterburn, and M. R. Stern N S. Vision and Sport: A review of the literature. Journal of American Optometry Association, 1982. 53 (8): 627-33.

18- Vaeyens, R., Lenoir, M. Williams, A. M., Mazyn, Phillippartes R. M. The Effect of task constraints on visual search behavior and decision making in youth soccer players. J Sport Exercise Psychology 2007. 29 (2): 147-69.

Ward, P. \& Williams, A. M. Perceptual and cognitive skill development in soccer: the multidimensional nature of expert performance. Journal of sport \& exercise psychology, 2003. 25, 93-111.

Williams, A. M. \& Ericsson, K. A. Perceptual - cognitive expertise in sport: some considerations when applying the expert performance approach. Human Movement Science, 2005. 24: 283-307.

Williams, A. M. \& Ericsson, K. A. Perceptual - cognitive expertise performance approach, Human Movement Science, 2005. 24. 283-307.

Williams, A. M. \& Hodges, N. J. Practice, Instruction and skill acquisition in soccer: Challenging. Tradition. Journal of sport science. 2005. 23 (6), 637-650.

Williams A. M., Ward, P. Knowles, J. M. \& Smeeton N. J. Perceptual skill in a real-world task : Training, instruction and transfer in tennis. Journal of Experimental Psychology. 2002; 48: 151-166.

Williams, A. M. \& Davids, K. Visual search strategy, selective attention and expertise in soccer. Research Quarterly for Exercise and Sport, 1998. 69: 111-128.

Yuan Y. W. Y, Fan X, Chin M \& So R. C. H., Hand-eye co - ordination and visual reaction time in elite badminton players and gymnast. New Zealand Journal of Sports Medicine, 1995. 23 (3): 19-22.

Zhang, J. \& Watanabe, K. Difference in saccadic latency and express saccades between skilled and novice ball players in tracking predictable and unpredictable targets at two visual angles. Percept Mot Skills, 2005. 100(3): 1127-36.

Zwierko. T. Differences in Peripheral Perception between Athletes and Nonathletes. Journal of Human Kinetics $2007,19,53-62$.

\section{Corresponding author}

\section{Ahmad Ghasemi}

PhD student in Research and Science Branch of Islamic Azad University.

Number 31, Tavakoli Ave, Jannat abad St, Tehran, Iran.

Phone /Fax:+989122778728

E-mail: a_gh_m2003@yahoo.com. 